\title{
RAZÃO, PENSAMENTO E SOCIEDADE: REFLEXÕES A PARTIR DE JEAN BAUDRILLARD
}

Reason, thought and society: reflections from Jean Baudrillard

Manoel Ribe iro de Moraes Junior ${ }^{1}$

UEPA - Pará/ Brasil

\begin{abstract}
RESUMO: Este artigo é resultado de um levantamento analítico dos conceitos pósmarxistas, pós-psicanalistas e pós-estruturalistas proposto por Jean Baudrillard. A virada epistemológica proposta por Baudrillard avança para além das categorias fixas de antropologia cunhadas na tradição filosófica, assumindo aspectos categóricos do desejo e da razão como ambiguidades predominantes nas ações humanas..
\end{abstract}

Palavras-chave: Sociedade. Humano. Desejo. Economia. Baudrillard.

ABSTRACT: This article is the result of an analysis of post- Marxist, postpsychoanalysts and poststructuralist concepts proposed by Jean Baudrillard. The epistemological turn proposed by Baudrillard goes beyond the fixed categories of anthropology, assuming categorical aspects of elan and reason as predominant ambiguities in human actions.

Keywords: Society. Human Economy. Elan. Baudrillard. ${ }^{1}$ Professor do Programa de Ciências da Religão da Universidade Estadual do Pará, Doutorado em Ciências
da Religião . E-mail: manoelribeiromoraesjr@gmail.com 


\section{Notas Introdutórias}

Jean Baudrillard é um sociólogo francês que repensa a "ação" e a "sociedade" a partir de flertes teóricos e tons de ironia desconstrutivista, procurando sempre revelar a dinâmica de criação dos signos que operam as representações sociais de forma alternativa às teorias tradicionais. Desta maneira, ele põe em xeque as antigas teorias sociais que se sustentavam a partir de um sistema tipológico restritos e sob polaridades fixas: material/ideal, objetivo/subjetivo, coletivo/individual, macro/micro. O pensamento de Baudrillard é expressão de um tempo dinâmico e plural, mas que não se aplica a desvendar a significação de uma hipotética pós-modernidade, tal como Jean-François Lyotard ou mesmo o filósofo italiano Gianni Vattimo.

Para o pensador francês, é contraproducente transformar a pós-modernidade em um sistema de interpretação ou mesmo em uma meta-narrativa, pois tal posição de pensamento evocaria para si o status de referencial do necessariamente novo - algo que a levaria ser nada mais que uma nova imagem da modernidade. Baudrillard repensa as Ciências Humanas (psicanálise, filosofia, economia, sociologia etc) focalizando o deslocamento que os objetos sofrem nos sistemas de constituição significativa, dando espaço para a primazia de um sistema de signos auto-referentes e sem ordenamentos lógico-formais.

Jean Baudrillard retoma a tradição analítica da sociedade inflacionando necessariamente a ideia e o papel social do desejo - categoria pertinentemente provocada por Jacques Lacan. Com ela, se pensará a ação, a dinâmica da economia e da política, a partir das propensões humanas ao desejo - inclusive quando o ser humano se põe a uma ação racional.

Este pensador francês também não se poupa em criticar Marx, Freud e outros analistas sociais, entendendo que estes estudavam a dinâmica humana não pelo que ela revela mas por aquilo que eles mesmos entendiam de ordenamento social. Este artigo é resultado de um levantamento analítico dos conceitos pós-marxistas, pós-psicanalistas e pós-estruturalistas proposto por Jean Baudrillard. A virada epistemológica proposta por Baudrillard avança para além das categorias fixas de antropologia, assumindo aspectos categóricos do desejo e da razão como ambiguidades predominantes nas ações humanas. 


\section{A Desfundamentação do pensamento, da ação e da sociedade.}

Sou um dissidente da verdade. Não creio na ideia de discurso de verdade, de uma realidade única e inquestionável Desenvolvo uma teoria irônica que tem por fim formular hipóteses. Estas podem ajudar a revelar aspectos impensáveis. Procuro refletir por caminhos oblíquos. Lanço mão de fragmentos, não de textos unificados por uma lógica rigorosa. Nesse raciocínio, o paradoxo é mais importante que o discurso linear. Para simplificar, examino a vida que acontece no momento, como um fotógrafo. Aliás, sou um fotógrafo (BAUDRILLARD, 2003).

A sedução desloca a verdade. Ela é a antítese das formas unívocas e objetivas da comunicação. A sua manifestação não pode nem mesmo ser entendida à luz da psicanálise recorrendo à distinção entre o discurso latente e o manifesto. Para a psicanálise, o discurso manifesto é sempre atraído pela vida submersa de um mundo diretor, verdadeiro mesmo que submerso. Já o discurso latente é o fio condutor do discurso manifesto, pois dele emergem as verdades abscônditas. Porém, a sedução não se origina das verdades imersas, profundas ou infra-estruturais. Ela simplesmente sobrevive às margens superficiais do sentido, do experimentado, resistindo às organizações profundas e, ainda mais, atraindo para si o poder de construção das mensagens.

A massa realiza realiza esse paradoxo de não ser um sujeito, um gruposujeito, mas de também não ser um objeto. Todas as tentativas para fazer dela um sujeito (real ou mítico) deparam com uma espantosa impossibilidade de tomada de consciência autônoma. Todas as tentativas para fazer dela um objeto deparam com a evidência inversa da impossibilidade de uma manipulação determinada de massas ou de uma apreensão em termos de elementos, de relações, de estruturas e de conjunto" (BAUDRILLARD, 1993, p. 30).

O conceito de sedução força Baudrillard a criticar as teorias de Sigmund Freud e de Ferdinand de Saussure. A psicanálise freudiana descarta a sedução de sua primazia: a autoreferencialidade. Pois para o psicanalista austríaco, a ilusão e a efemeridade são dependentes e originárias de seus opostos: o verdadeiro e do perene. Do mesmo modo, Saussure insistiu na lógica da substituição, postulando um sub-nível universal da linguagem: a linguística. $\mathrm{O}$ sentido e a ordem são forças narcisistas que o pensamento teórico busca deflagrar definitivamente no ordenamento do mundo. 
Nas sociedades capitalistas, onde os signos sobrevivem cada vez mais independentes dos objetos, o real não se orienta mais sobre verdades ônticas, mas sobre paixões pelo desvio, pela sedução. O real não manifesta coisas e nem verdades, mas vontades e desejos.

Para a sedução, o desejo não é um fim, é uma aposta hipotética. Mais precisamente, a aposta é de provocação e de decepção do desejo, cuja única verdade consiste em cintilar e ser decepcionado - o próprio desejo abusando de sua potência, que só lhe é dada para lhe ser retirada. Ele nem ao menos saberá o que lhe acontece. Pois aquele ou aquela que seduz pode realmente amar ou desejar; só que mais profundamente (ou superficialmente, se se quer, no abismo superficial das aparências) um outro jogo que nenhum dos dois conhece desenrola-se e do qual os protagonistas do desejo são apenas figurantes (BAUDRILLARD, 1991, p.99).

É a partir da inversão especulativa proposta por Baudrillard, podemos entender como a psicanálise e as ciências humanas em geral são apáticas às forças da sedução. Não é por menos, mesmo críticos às suas tradições, eles ainda se mostram aliados aos ideais da metafísica platônica. Estes saberes sobre o mundo social rejeita as pulsões da sedução que habitam o convívio humano, porque eles acreditam no hinterwelt (mundo oculto) racional e distintivo. Todavia, estas teses ainda se apoiam numa convicção oculta que, insistentemente, aposta na inteireza cognitivista do ser humano. Mas, com a derrocada do socialismo burocrático e desencantado a favor da expansão de um capitalismo sofisticado e cínico, despertou-se a compreensão de que o prazer e a euforia também são expressões da humanidade que sobrevive ávida de desejos: "tal euforia dinâmica atua como antítese das satisfações estáticas e imobiliárias da família e como parênteses na realidade social" (BAUDRILLARD, 93, 75). Nas experiências dos encontros sociais e das imagens publicitárias ou não, a sedução é descoberta como algo preponderante, mas que não pode ser representado de forma precisa, unívoca. Ela não distingue coisas, simplesmente convida a um encontro. E este encontro não é aprofundamento, ultrapassagem ou revelação de tudo que é visível. Não há nada mais que imagens, como as do espelho: objeto que sobrevive da imagem manifesta. A incidência da sedução com o seduzido transgride a lógica do real, da vida e da morte. A sedução transcende o mundo do real. 
Seduzir é fazer figuras jogar entre si, fazer jogar entre si signos roubados a sua própria armadilha. A sedução jamais é o resultado de uma força de atração dos corpos, de uma conjunção de afetos, de uma economia de desejos; é preciso que intervenha um engano e misture as imagens, é preciso que uma tirada de repente separe coisas indivisas: assim a primeira carta traz consigo a tentação irresistível de ser reescrita para outra mulher, numa espécie de funcionamento irônico autônomo cuja própria idéia é sedutora. Jogo sem fimao qual os signos se prestam espontaneamente por uma ironia sempre disponível. Talvez eles queiram ser seduzidos, talvez, mais profundamente que os homens, desejam seduzir e ser seduzidos (BAUDRILLARD, 1991, 118).

Para Baudrillard, a virada hermenêutica da razão ainda não reverencia a dinâmica relacional que as sociedades intermedeiam em suas expressões religiosas, políticas ou econômicas. Pois as relações sociais não se impõem como vontade de coisas ou manifestas em expressões portadoras de significações delimitáveis, mas simplesmente como vontadesde-si (ou vontades-em-si). Todas as Ciências Humanas insistem em conhecer a dimensão da subjetividade e da sociabilidade a partir de referenciais coisificantes ou logicamente significantes. Porém o jogo social é regrado pela vontade e ela transcende a lógica das coisas e dos sentidos unívocos.

Baudrillard anticategoriza as dimensões científicas do sentido. De modo oposto aos “pensadores guardiãs" do esclarecimento, o sociólogo francês encontra bons motivos para esta orientação investigativa: as consequências de uma (des ou neo)organização do mundo contemporâneo impulsionado pela liberação do discurso sexual e, respectivamente, a proliferação das figuras do desejo. Não é por menos, esta supervalorização do sexo e de seus signos, orientados por referências hiper-realistas do gozo, contrastam com os modelos patriarcais e masculinos de pensamento e mundo. Este estádio paradigmático da sociedade hodierna eclode a fragilização do absoluto, dos princípios unívocos e universais de referência. Portanto, o único princípio observável é o da incerteza e ele regerá progressivamente a razão política e econômica.

Quando a economia absorve o princípio do desejo, ela passa a operacionalizar sem as restrições próprias de um sistema coerente. A economia não se guia mais pelo princípio da carência imediata, mas das infinitas possibilidades abertas pelo espectro do desejo. Segundo Baudrillard, "é o espectro do desejo que persegue a realidade defunta do sexo. O sexo está em toda a parte, exceto na sexualidade” (BAUDRILLARD, 1991, pp 9-10). 
O desejo não se põe como o outro das formas fálicas do sexo, mas como alvo, como atração universal: pura sedução. A sedução tem a sua dinâmica no domínio do universo simbólico,

em termos de sedução - não mais em termos de uma estrutura e de oposição distintivas mas de reversibilidade sedutora - um universo onde o femenino já não é o que se opõe ao masculino mas o que seduz o masculino(BAUDRILLARD, 1991, p. 12).

As dimensões de sexo e poder do masculino pousam sobre referências definidas e estabelecidas. A verdade não pode ser comensurada nos jogos da sedução. Pois, nas regras do poder a sedução dirige-se a realidades definidas. No entanto, quando mudada as regras dos jogos simbólicos do real, a sedução des-finaliza os objetivos do desejo.

Mas para esclarecer a temática do desejo, Baudrillard procura desvendar a presença do corpo na ação do desejo: é uma metáfora ou definitivamente o destino anatômico do desejo? O desejo é volúpia, é força que transcende às formas monolíticas da ética e da verdade. A anatomia, o corpo, tem papéis, formas e funções. Enquanto isso, o desejo, forças das seduções, opõe-se "radicalmente à anatomia como destino. Somente a sedução rompe com a sexualidade distintiva dos corpos e a inelutável economia fálica dela resultante" (BAUDRILLARD, 1991, 15). Ë desta maneira que Baudrillard critica a economia clássica e a Crítica à Economia Política de Marx. Os signos não se baseiam em infraestruturas, mas em movimentos criativos, em transcendências. A verdade é a própria aparência. "De nada serve jogar ser contra ser, verdade contra verdade; eis aí a armadilha de uma subversão dos fundamentos, quando basta uma ligeira manipulação das aparências" (BAUDRILLARD, 1991, pp. 15-16).

A expressão ligeira, aparente, do arquétipo feminino não pode deixar ser consumido em tentativas, como se recalcadas - a aí valeria o diagnóstico da psicanálise freudiana -, de substituir a profundidade do masculino: "as mulheres fariam bem em se deixar seduzir por essa verdade, pois aí reside o segredo de seu poder, que estão quase a perder, levantando a profundidade do feminino contra a do masculino" ((BAUDRILLARD, 1991, pp. 15-16). O fato feminino não é a superficialidade contra a profundidade masculina. Este antagonismo só sobrevive sob as amarras do poder masculino. 
Para Baudrillard, o mundo simbólico feminino não distingue superfície e profundidade, autêntico e artificial: "o masculino é certo, o feminino é insolúvel" (BAUDRILLARD, 1991, p. 16). Deste modo, não é possível distinguir o real da simulação, no entanto, sabe-se que na insolubilidade da simulação, a sedução é a experiência fundamentalmente ambígua no que concerne ao feminino: somente ela pode ultrapassar a simulação.

\section{A eterna ironia da comunidade}

A feminidade é o princípio da incerteza e, por isso, ela suspende as distinções. No entanto, é como indeterminitude que surge a maior incerteza: a "representatividade da feminidade" (p. 17). Para melhor explorar as novas imagens do mundo da sedução, Baudrillard enfoca a dinâmica do travestismo. Nos atos do travestismo não distinção de papéis e nem de identidades sexuais. Para eles o que os atraem são os signos da sedução. Neste jogo o mais importante não é definir as formas de sedução a partir das distinções sexuais, mas sim jogar empenhados em ritualizar as seduções per se. O sexo não rege as seduções, mas é uma das situações da sedução. O objetivo da sedução não é a verdade, mas o fascínio. Platão e toda a metafísica clássica consubstanciaram verdade e fascínio. Mas, na contemporaneidade, as duas faces não são de uma mesmo corpo. Janus morreu, e tanto a verdade como o fascínio se mostram duas pessoas completamente distintas: "fascínio perdido quando o sexo real transparece ... A sedução sempre é mais singular e sublime que o sexo, e é a ela que atribuímos preço maior" ((BAUDRILLARD, 1991, p. p. 18). Deste modo, a objetividade das coisas e das relações são transubstanciadas nos signos subjacentes aos jogos da sedução. Não há mais há mais porquê considerar a velha casuística da latência sugerida pela psicanálise, "tudo se representa na vertigem dessa reversão, dessa transubstanciação do sexo nos signos, que é o segredo de toda a sedução" (BAUDRILLARD, 1991, p. 18). Desta maneira, a feminidade ela transcende o corpo e produz o desejo: a maquilagem é mais forte que as formas do corpo, o desejo transcende a imagem real. 
Desta maneira podemos colocar um distintivo histórico: do passado até hoje contemplamos o poder da falocracia contra as formas atuais da sociedade revolucionada pelo desejo. Parte sim. No entanto, cabe também a tese de que o mundo patriarcal sobrevive como força de resistência à autêntica forma de sedução que move a todos os sentidos e relações. Bem, desta maneira, podemos compreender como as instituições se tornaram menos razoáveis e mais coercitivas - poder é estabelecido força vigilante, contra as silenciosas pulsões que permeiam constantemente todos os espaços da vivência: "os homens erigiram seu poder e suas instituições apenas para contrariar os poderes originais bem superiores da mulher. Não é a inveja do pênis o motor; ao contrário, é o ciúme do homem pelo poder de fecundação da mulher. Esse privilégio da mulher é imperdoável; era preciso inventar a qualquer preço uma ordem diferente, social, política e econômica masculina, onde esse privilégio natural pudesse ser diminuído" (BAUDRILLARD, 1991, p.22).

A feminidade não produz ordem de valor. Ela não é produtora, mas sedutora. Ë fraco o mito da guerra dos sexos. Ë fraco também a tese de que houve um combate na história das civilizações, para o controle sexual das sociedades. O poder dos homens sempre se estabeleceu para o controle da força que o enfraquecia: o desejo via a sedução. Por isso, era preciso a moral, a religião, o poder. No entanto, a mono-sexualidade encartada no processo de controle da sexualidade, absteve os homens das formas do gozo conciliar, conspirativo. Desta maneira, o patriarcalismo procura exonerar as mulheres das pressões e das forças de controle a partir de propagandas liberais para a garantia dos diretos individuais e de salvaguarda dos direitos sexuais. No entanto, a regência masculina não observou que as formas da sedução não seguem direitos e nem garantias constitucionais.

\section{Simulações e Seduções}

Para Baudrillard, os séculos contemporâneos são marcados pela "história violenta" dos grandes conflitos: de um lado o armamentista (duas grandes guerras) e o políticoeconômico (guerra fria); e, do outro, a ascensão do cinema como veículo imaginário dos mitos. Então, o que é o século XX: ápice da história erguido pelo advento do capitalismo e da tecnologia científica, a radicalização social da tecnologia industrial e o cumprimento da promessa iluminista, ou simplesmente a experimentação de uma recriação do despotismo e das narrativas lendárias? 
O cotidiano é marcado pelas estratégias de mercado e de guerra. Tal como Lukacs (1989) afirmou, as experiências do imaginário comum se adequaram às formas do capital, da mercadoria e do dinheiro. Não há espaço mais simbolismos tradicionais. A concretização das relações sociais na ação da negociação (a moral do capital) e dos conflitos (a ética do reconhecimento pela guerra), expulsou do mundo da vida as narrativas simbólicas: a celebração da técnica sentenciou a vitória da mecânica sobre o mito narrativo. Porém, para sobreviver, o mito se refugia no espaço aberto pela própria tecnologia às expressões da arte: o cinema. "O mito, expulso do real pela violência da história, encontra refúgio no cinema" (BAUDRILLARD, 1991, p. 59).

O Impulso coisificante que tomou conta da ordem do agir e do pensar, o mesmo que expulsou o mito das aventuras imaginativas do dia-a-dia, fez da história a sua outra vítima. Só existe um início nostálgico quando se considerar a possibilidade de haver diferenças com o presente, só há histórias somente quando se considerar o presente social como encontro de origens diversas. História ou histórias são visões de mundo social que não se ajustam às exigências presentes de planificação, neutralização e congelamento da identidade sócioglobal. Porém, onde encontrar então a narrativa outra do presente: nos mitos ou na história? Bem, independente da escolha, ambos habitam o cinema. Narrativas objetivas ou metafóricas, suspensas de seu habitat originário: o mundo da vida, agora elas sobrevivem nos ecrãs.

O esvaziando da política, da história e dos mitos, considerando as suas possibilidades espontâneas na práxis social, haja vista que elas sobrevivem em realidade virtuais: os personagens históricos, mitológicos e políticos dos cinemas e das universidades são celebrados como presentes, mas que, inconscientemente, são sabidos como mortos: um réquiem alemão (os poucos que insistem na categoria da universalidade) ao mito, à história e à política. No entanto, sendo o ser humano um ente do ser e, por isso, do sentido, ele sofre de uma agonia por causa da separação silenciosa entre o racional e o real.

Mas por que a espera pela ressurreição da história? A história é mito na sociedade de nossa época, um referencial perdido - mas necessário. É a partir dela que se constrói as expectativas salvacionistas ou catastróficas do presente, é a certeza de que o mundo traz 
referências originárias das quais tudo pode ser avaliado e, assim, a vida ganha um sentido linear. Mas o que é essa história, o mito moderno, num mundo não articulado mas a partir das referências. Por viver pela expectativa de um passado ordenado (ao necessariamente bom ou mal), a possibilidade aberta pelo presente é o da náusea ou da angustia: um presente aberto, infinito e sem sentido, vivendo desancorado em pleno mar. Na época presente é inútil se guiar pelos referências metafísicos do passado: verdade, bem e belo.

Na presente época não houve espaço para o vazio. A descoberta da possibilidade da facticidade do vazio provocou um trauma não consolidado. Baudrillard, para tanto, recorre à teoria do fetichismo da psicanálise freudiana. A sociedade celebra a sua imagem nas telas dos cinemas. Não interessa as construções: fascismo ou etc. O que importa é a rejeição do nada, do caos ou da confusão. A perspectiva de Baudrillard é bem calara: não interessa o sentido: o uno e a identidade sobrevivem independentemente das suas imagens. Não interessa quem é a história, Deus, a moral ou a política: o que importa é a ordenação do real. “Corra, corra que o tumulto ta formado. Vem cá vem ver, vem cá vem ver, que dentro do tumulto pode estar você".

Segundo Fabiano Oliveira (OLIVEIRA, S/D),

Conceber simulacros é imaginar a substituição do real pelos signos do

real, isto é, o real não é mais referência para a produção do sentido, mas os sentidos já estão dados e se constituem no padrão aos quais os acontecimentos deverão se enquadrar. As teorias apresentadas trataram de nos esclarecer ao mesmo tempo em que causavam a perplexidade de um possível mundo ilusoriamente real que precisa ser apreendido em sua profundidade, pois dele todos participamos tanto como produtores quanto como consumidor.

A história no cinema é jogo da promessa do concreto pelo enredo simulado: a sedução não promete o real. A História é hiper-real. A simulação quanto mais convence da sua concretude, mas distante ela fica do real. O cinema e a sua trajetória: do mais fantástico ou mítico ao realístico e à hiper-realístico (BAUDRILLARD, 1993, p.64). "O cinema pode hoje colocar todo o seu talento, toda sua técnica ao serviço da reanimação daquilo que ele próprio contribuiu para liquidar. Apenas ressuscita fantasmas e aí se perde ele próprio”. 


\section{Conclusão}

Baudrillard aprofunda os problemas (aporias) nos estudos sociais. Para o pensador, a sociedade não pode ser pensada como homóloga a uma antropologia atômica, ordenada e una. Isso seria uma compreensão ainda mitológica de sociedade. Por isso, Baudrillard lança mão de aspectos fundamentais da clássica epistemologia das ciências humanas para entender o universo da ação humana. O mundo não se faz mais num sentido que é esperado, e sua expectativa é frustrada silenciosamente porque o sentido do real-sem-sentido lhe é posto como uma grande simulação. A nossa era é a da história e da política simulada.

\section{Referências}

BAUDRILLARD, Jean. Simulacros e simulação. Lisboa: Relógio D’Água, 1991 a.

. Da sedução. Campinas: Papirus, 1991 b.

. O sistema dos objetos. São Paulo: Editora Perspectiva, 1993.

. A troca simbólica e a morte. São Paulo: Edições Loyola, 1996.

. A ilusão vital. Rio de Janeiro: Civilização Brasileira, 2001.

. À Sombra das maiorias silenciosas. O fim do social e o surgimento

das massas. São Paulo: Brasiliense, 1993

. Telemorfose. Rio de Janeiro: Mauad, 2004.

Freud, S. A interpretação das afasias: um estudo crítico. Lisboa, Edições 70.

LUKÁCS, G. História e consciência de classe: estudos de dialética marxista. Rio de Janeiro: Elfos Ed.; Porto: Publicações Escorpião, 1989.

LYOTARD, J. F. A Condição Pós-moderna. Rio de Janeiro: José Olympio, 1979

MARX. Karl. Contribuição à crítica da economia política. Trad. Florestan Fernandes.

2.ed. São Paulo: Expressão Popular, 2008 .

OLIVEIRA, Fabiano. Conhecendo o simulacro.

http://www.revistas.usp.br/caligrama/article/viewFile/61336/64276 (Acessado

$13 / 04 / 2015,19.49$ )

VATTIMO, G. O Fim da Modernidade: Niilismo e Hermenêutica na Cultura Pósmoderna. São Paulo: Martins Fontes, 1985.

SAUSSARE, F. Curso de Lingüística Geral. São Paulo: Cultrix, 2004. 